\title{
Effect of Single-Session, Cryogen-Cooled Monopolar Radiofrequency Therapy on Sexual Function in Women with Vaginal Laxity: The VIVEVE I Trial
}

\author{
Michael Krychman, MD, Christopher G. Rowan, PhD,2, Bruce B. Allan, MD, PhD, FRCS(C), \\ Scott Durbin, $\mathrm{MPH}^{4}$ Ashley Yacoubian, BSc, ${ }^{4, *}$ and Deborah Wilkerson, $\mathrm{PhD}^{4}$
}

\begin{abstract}
Objective: This subanalysis of the VIVEVE I trial aimed to evaluate the impact of cryogen-cooled monopolar radiofrequency (CMRF) therapy, for the treatment of vaginal laxity, on the domains of sexual function included in the Female Sexual Function Index (FSFI).

Materials and Methods: The VIVEVE I clinical trial was prospective, randomized, single-blind, and Shamcontrolled. Nine clinical study centers in Canada, Italy, Spain, and Japan were included. This subanalysis included premenopausal women with self-reported vaginal laxity who had $\geq 1$ term vaginal delivery and a baseline FSFI total score $\leq 26.5$, indicating sexual dysfunction. Enrolled subjects were randomized $(2: 1)$ to receive CMRF therapy [Active $\left(90 \mathrm{~J} / \mathrm{cm}^{2}\right)$ vs. Sham $\left(\leq 1 \mathrm{~J} / \mathrm{cm}^{2}\right)$ ] delivered to the vaginal tissue. Independent analyses were conducted for each FSFI domain to evaluate both the mean change, as well as the clinically important change for Active- versus Sham-treated subjects at 6 months post-intervention.

Results: Subjects randomized to Active treatment $(n=73)$ had greater improvement than Sham subjects $(n=35)$ on all FSFI domains of sexual function at 6 months postintervention. The analysis of covariance change from baseline analyses showed statistically significant improvements, in favor of Active treatment, for sexual arousal $(p=0.004)$, lubrication $(p=0.04)$, and orgasm $(p=0.007)$. In addition, Active treatment was associated with clinically important and statistically significant improvements in sexual desire [Odds ratio $(\mathrm{OR})=3.01$ (1.11$8.17)]$, arousal $[\mathrm{OR}=2.73(1.06-7.04)]$, and orgasm [OR $=2.58(1.08-6.18)]$.

Conclusions: This subanalysis showed CMRF therapy is associated with statistically significant and clinically important improvements in sexual function in women with vaginal laxity. These findings provide the first randomized, placebo-controlled energy-based device evidence for functional improvements associated with a nonsurgical modality for a highly prevalent and undertreated condition.
\end{abstract}

Keywords: vaginal laxity, vaginal looseness, radiofrequency therapy, surface cooled, nonsurgical, sexual function, FSFI, FSFI domains

\section{Background}

$\mathbf{F}$ EMAle SeXual Dysfunction (FSD) is a common condition, estimated to occur in $\sim 40 \%$ of women in the United States. However, a recent study of 3000 women found that only $1 / 3$ of women with a distressing sexual problem seek help from a healthcare professional, and only 6\% schedule a visit to specifically discuss their sexual concerns. ${ }^{1,2}$ While sexual dysfunction is estimated to be of higher prevalence for women $(\sim 40 \%)$ versus men $(\sim 30 \%)$, there is currently only one FDA-approved medication for FSD, specifically for hypoactive sexual desire disorder. ${ }^{3,4}$

\footnotetext{
${ }^{1}$ Southern California Center for Sexual Health and Survivorship Medicine, Newport Beach, California.

${ }^{2}$ Collaborative Healthcare Research and Data Analytics (COHRDATA), Santa Monica, California.

${ }^{3}$ Allan Centre, Calgary, Alberta, Canada.

${ }^{4}$ Viveve Medical, Inc., Englewood, Colorado.

*This author is no longer employed by Viveve Medical.

(C) Michael Krychman et al. 2018; Published by Mary Ann Liebert, Inc. This Open Access article is distributed under the terms of the Creative Commons Attribution Noncommercial License (http://creativecommons.org/licenses/by-nc/4.0/) which permits any noncommercial use, distribution, and reproduction in any medium, provided the original author(s) and the source are cited.
} 
Key factors for women's sexual dysfunction include physical change(s) in a woman's vaginal tissue integrity secondary to childbirth, aging, or other connective tissue influencers, which can be associated with greatly reduced physical sensation during intercourse and diminished sexual satisfaction. ${ }^{3-5}$ These physical changes to the vagina (sometimes referred to as "vaginal laxity" in the medical and scientific literature) can cause the vaginal opening to feel looser to the woman and/or her sexual partner during penetration.

The exact prevalence of vaginal laxity after childbirth and other etiologies has yet to be determined. However, the association of patient-reported vaginal introital laxity with associated distressing sexual function is reported in the literature by both healthcare providers and by patients themselves. Vaginal laxity is a frequently unreported medical condition ${ }^{6-8}$ that negatively impacts female sexual function, self-image, and may directly impact quality of life (QOL). ${ }^{9-12}$ A recent study showed $50 \%$ of parous women were concerned about vaginal laxity, yet $\sim 80 \%$ of them failed to discuss their concern with their obstetrician/gynecologist. ${ }^{5}$ A study of urogynecologists showed vaginal laxity negatively impacts their patients' QOL, sexual function, sexual satisfaction, and relationship happiness; they further identified the vaginal introitus as the most frequently cited location of laxity, with symptoms arising from changes in the integrity of both muscle and vaginal tissue. ${ }^{6}$

Vaginal laxity reports are based on patient-reported outcome instruments, including the patient's perception of her own vaginal looseness and/or symptoms of the vaginal looseness related to sexual function. This is due to the fact that presently, no reliable objective instrument exists to accurately measure, diagnose, or classify vaginal laxity or to furthermore correlate vaginal size/anatomy with sexual function. ${ }^{13-19}$

A recent review of the literature found just five examples of nonsurgical treatments that were published in peer-reviewed literature or on clinicaltrials.gov. ${ }^{20}$ Of these, one was for muscle training, one was using the Erbium:YAG laser, and three were using a radiofrequency device with cryogen cooling. Radiofrequency (RF) energy has a long history of use in sensitive tissues, such as mucosal tissue in the vagina, ${ }^{21-23}$ cornea, ${ }^{24-26}$ and skin. ${ }^{27,28}$ The device used in the VIVEVE I trial delivers dual-mode, monopolar, radiofrequency energy with cryogen cooling to protect the superficial mucosa, while enabling heat to reach deeper into the underlying tissue layers. This dual-mode therapy uses heating and cooling to activate fibroblasts to produce new collagen and stimulate remodeling of vaginal tissue without evidence of fibrosis or underlying scarring, thereby providing additional support to the connective tissue matrix of the introitus and associated genitopelvic structures. ${ }^{21-23,27,29-37}$

Preclinical studies of cryogen-cooled monopolar radiofrequency (CMRF) delivered to the vaginal introitus demonstrated nonfibrotic collagen deposition up to 6 months posttreatment. $^{30,31}$ Two single-arm, pilot studies in women with vaginal laxity showed CMRF therapy was safe and effective at 6 and 12 months postintervention. ${ }^{14,15}$ Also, the completion of this VIVEVE I randomized clinical trial now provides the first comparative effectiveness data between a standard clinical treatment and a Sham treatment to support the safe and effective use of CMRF therapy for the treatment of vaginal laxity.

This subanalysis of the VIVEVE I trial aimed to evaluate the impact of CMRF therapy of the vaginal introitus on each of the Female Sexual Function Index (FSFI) domains of sexual function. The VIVEVE I trial is the first randomized, placebocontrolled trial with a Sham arm of energy-based therapy for the treatment of vaginal laxity for improved sexual function. ${ }^{38}$

\section{Materials and Methods}

\section{Study design and research subjects}

The VIVEVE I study was a multicenter, prospective, randomized, single-blind Sham-controlled trial that was conducted between January 2015 and March 2016 at nine centers in Canada, Spain, Italy, and Japan. The VIVEVE I trial was registered at clinicaltrials.gov (NCT02261974). The research sites' principal investigators were obstetricians/gynecologists or urogynecologists based in private clinics or in associated divisions of larger academic or medical institutions. Written informed consent was obtained before screening. Local ethics committees or institutional review boards for each study center approved the overarching trial protocol, which adhered to the Declaration of Helsinki. The same assessments and procedures were carried out for all subjects, regardless of any site-specific required modifications (i.e., one additional inclusion criterion and a reordering of efficacy assessments).

Women presenting at the participating study centers with self-reported vaginal laxity were invited to participate in study screening. Printed media, radio, and Facebook ads were also used for patient recruitment. The VIVEVE I trial included premenopausal females ( $\geq 18$ years of age) with $\geq 1$ term vaginal delivery and self-reported vaginal laxity during sexual intercourse (classified by a score of $\leq 3$ on a Vaginal Laxity Questionnaire). Women were excluded from the trial if they had an abnormal genitopelvic exam, were currently pregnant or breastfeeding, had a history of genital fistula or a thin rectovaginal septum, or had clinically significant pelvic organ prolapse. For the purpose of evaluating the impact of CMRF therapy in subjects with preexisting sexual dysfunction, this subanalysis was restricted to female subjects with sexual dysfunction, as defined by an FSFI total score $\leq 26.5$ at the screening visit.

\section{Randomization and intervention}

Study subjects meeting the inclusion/exclusion criteria were randomized 2:1 to receive either Active or Sham treatment in an effort to maximize the amount of safety data that were gathered. The Active group was randomized to receive a CMRF energy dose of $90 \mathrm{~J} / \mathrm{cm}^{2}$; the Sham group was randomized to receive a nontherapeutic energy dose of $\leq 1 \mathrm{~J} / \mathrm{cm}^{2}$.

Regardless of the randomized treatment assignment, subjects received 1 outpatient treatment of up to 110 pulses. For both treatment arms, a standard coupling fluid was applied to the vaginal introitus and device handpiece to ensure effective CMRF transfer. Figure 1 shows the Viveve System with the handpiece and a treatment tip attached. Figure 2 provides a closer look at the handpiece and treatment tip. For both treatment arms, a single-use tip (Active or Sham) delivered CMRF therapy circumferentially to the vaginal mucosal surface, avoiding the urethral area, in $\sim 0.5 \mathrm{~cm}$ overlapping intervals for five complete passes. Each treatment took $\sim 30$ minutes to complete. A treatment consisting of less than 80 pulses was considered a partial treatment; subjects who received a partial treatment were asked to continue in the study at least until the 1-month follow-up to ensure that no adverse effects were observed. No prescribed pretreatment or posttreatment medications were required. 


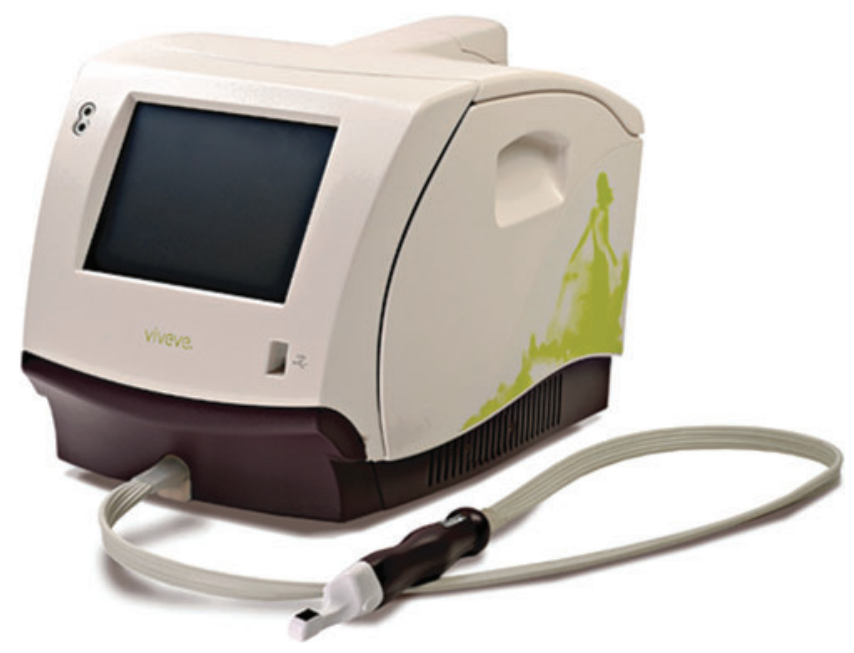

FIG. 1. Investigational product: Viveve System.

All subjects received the same follow-up and care; hence, they were treated exactly the same throughout the study, regardless of their assigned randomization group. The only exception was that the treatment tip used for the Sham group was specially programmed to deliver $\leq 1 \mathrm{~J} / \mathrm{cm}^{2}$. This allowed the subjects to remain blinded to the treatment they received during the procedure. Postprocedure, both Sham and Active subjects were requested to refrain from vaginal intercourse or the use of tampons for a period of 10 days.

\section{Follow-up and study exit}

The FSFI questionnaire was administered at the screening visit (baseline) and at months 1, 3, and 6 postintervention. Adverse events were also recorded at these study intervals. Study exit occurred after completion of the 6-month followup visit, unless the subject requested to leave the study early or was lost to follow-up. In the Active group, eight subjects did not complete the 6-month follow-up visit for a variety of reasons: two subjects received partial treatment and were not required to complete the 6-month visit; three subjects withdrew consent; two subjects were lost to follow-up, and one subject sustained an injury that prevented her from continuing in the trial. This subject sustained a herniated disk from a skiing accident that left her incapable of intercourse as she recovered, and she was thus unable to provide appropriate

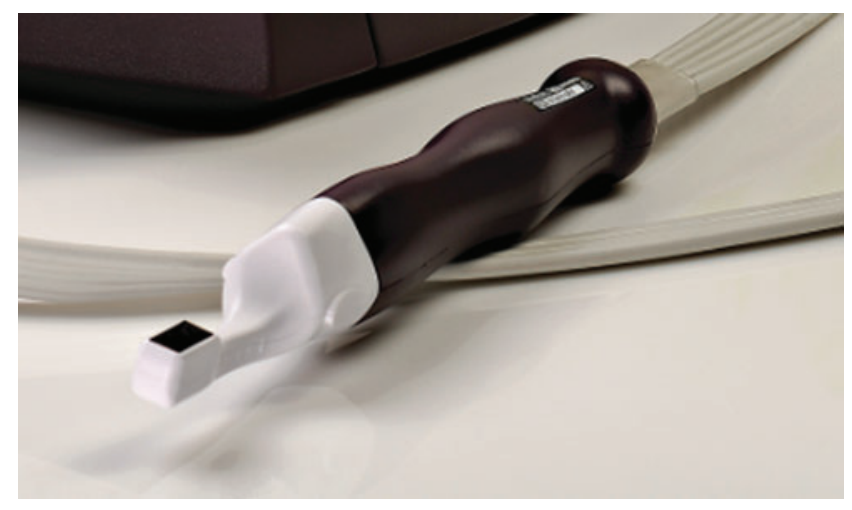

FIG. 2. Investigational product component: handpiece with treatment tip. responses to the study questionnaires. One subject in the Sham group, having received a partial treatment, was followed up until the 1-month visit; all other subjects in this randomization group completed their 6-month treatments.

\section{FSFI assessment}

The endpoint of focus for this publication, the FSFI, is a widely accepted, global assessment used in female sexual medicine trials, which has been validated in many languages and for a variety of patient populations. ${ }^{16,39}$ The formally validated English, Spanish, French, and Italian versions of the FSFI were used in this study.

The FSFI includes 19 questions (Supplementary Table S1; Supplementary Data are available online at www.liebertpub .com/jwh), categorized into 6 domains, which evaluate a woman's recent state of sexual function (i.e., within the past 4 weeks). The minimum and maximum scores for each domain range from 0 to 6 (except for the "Desire" and "Satisfaction" domains, where the minimum scores are 1.2 and 0.8 , respectively). The "Desire" domain includes two questions to assess sexual desire or interest. The "Arousal" domain includes four questions to assess sexual arousal and excitement during sexual activity or intercourse. The "Lubrication" domain includes four questions to assess lubrication and "wetness" during sexual activity or intercourse. The "Orgasm" domain includes three questions to assess the ability to reach orgasm or climax during sexual activity or intercourse. The "Satisfaction" domain includes three questions to assess satisfaction with their sexual relationship with their partner and overall sex life. The "Pain" domain includes three questions to assess pain or discomfort during and following vaginal penetration.

The domain scores combine to create a total score (range $2-36$ ). A total FSFI score $\leq 26.55$ is recognized in the medical literature as indicating sexual dysfunction. ${ }^{40}$ In validation studies, the FSFI demonstrated excellent discriminant validity for all domains of sexual function, including the ability to accurately discriminate sexual function from sexual dysfunction. ${ }^{41}$

Scoring for each FSFI domain and the FSFI total score are presented in Supplementary Table S2.

\section{Statistical analyses}

The VIVEVE I trial was powered to detect statistically significant and clinically important differences between the Active and Sham treatment groups for the primary outcome of "no vaginal laxity." The sample size for the VIVEVE I primary analysis was derived using the combined results from two single-arm pilot studies in the United States and Japan. ${ }^{14,15}$ It is well recognized that "placebo" or "Sham" effects can be substantial, especially for subjective endpoints such as assessments of health-related QOL, including the FSFI used to assess female sexual health in this trial. To obtain a causative treatment effect, the VIVEVE I trial employed the requisite two-arm design to distinguish a bona fide, causative treatment effect from either a placebo/Sham effect or chance alone. The secondary analyses (presented in this subanalysis) of the FSFI domains of sexual function included approximately two-thirds of the subjects included in the VIVEVE I trial. 
The first efficacy assessment included in this subanalysis was the change from baseline (CFB) to 6 months postintervention for each of the six FSFI domains of sexual function. The CFB analyses were determined using observed raw mean scores for each FSFI domain (calculated as the 6month value minus the baseline value). In addition, adjusted mean change (AMC) values were determined using analysis of covariance (ANCOVA) adjusted for the baseline FSFI domain value and treatment group.

The second efficacy assessment was to determine minimal clinically important differences (MCID) using receiver operating characteristics (ROC) and the cumulative distribution function. The MCID was estimated using anchor-based methodology, which relates the magnitude of change on each FSFI domain to an independent measure reflecting the extent of a subject's perceived treatment benefit (i.e., the anchor). Anchoring methodology and ROC were used to establish the minimum change (i.e., improvement) on each domain of sexual function that was clinically important (i.e., the MCID) at 6 months. The percentage of subjects who achieved the MCID for each FSFI domain assessment was determined. MCID odds ratios and 95\% confidence intervals were estimated using logistic regression adjusted for the baseline FSFI domain value and treatment group. The binary (yes/no) "anchoring" question used in the MCID analyses included a single question at each follow-up time point: "Overall, do you believe that you have experienced a meaningful benefit from the study treatment procedure?"

In addition, the FSFI total score mean values are included for Active- and Sham-treated subjects at baseline and 1, 3, and 6 months postintervention.

The analysis set, for this subanalysis, included randomized subjects with a baseline FSFI score $\leq 26.5$ who received complete or partial treatment and who completed the baseline and 6-month FSFI efficacy assessment. Post-hoc power calculations were not conducted and no adjustments were made for multiplicity. Results from these secondary analyses should be interpreted as exploratory and hypothesis generating. All analyses were compared using a two-sided significance level of 0.05 . The assumptions of normality of error distribution (i.e., homoscedasticity) and linearity were assessed for the ANCOVA analyses. Statistical analyses were conducted using STATA version 14 (Stata Corp. College Station, TX).

\section{Results}

\section{Participants}

Between January 2015 and March 2016, 108 subjects [Active treatment $(n=73)$ and Sham treatment $(n=35)]$ met all study inclusion/exclusion criteria, completed the baseline and 6-month FSFI assessment, and had a baseline FSFI total score $\leq 26.5$. Table 1 shows baseline characteristics for subjects in each treatment group. Overall, the baseline characteristics were similar for subjects in the Active and Sham groups.

\section{FSFI total score results}

Mean FSFI total score values at baseline and months 1, 3, and 6 are described in Figure 3. Baseline values were similar between Active and Sham groups. Subjects who received Active treatment showed greater overall FSFI improvement than Sham subjects. The mean FSFI total score for Active subjects improved from sexually "dysfunctional" to "func-
Table 1. Baseline Characteristics AND Maternal History

\begin{tabular}{|c|c|c|}
\hline & $\begin{array}{c}\text { Active } \\
\text { treatment }^{\mathrm{a}}\end{array}$ & $\begin{array}{c}\text { Sham } \\
\text { treatment }\end{array}$ \\
\hline $\begin{array}{l}\text { No. of subjects in the } \\
\text { analysis set }\end{array}$ & 73 & 35 \\
\hline \multicolumn{3}{|l|}{ Demographic data, mean (SD) } \\
\hline Age & $40.1(6.4)$ & $40.1(5.9)$ \\
\hline \multicolumn{3}{|l|}{ Age categories, $N(\%)$} \\
\hline$<35$ years & $14(19.2)$ & $7(20.0)$ \\
\hline $35-39$ years & $19(26.0)$ & $7(20.0)$ \\
\hline 40-44 years & $23(31.5)$ & $12(34.3)$ \\
\hline$\geq 45$ years & $17(23.3)$ & $9(25.7)$ \\
\hline \multicolumn{3}{|l|}{ Clinical data, mean (SD) } \\
\hline BMI & $24.5(5.0)$ & $25.1(6.3)$ \\
\hline \multicolumn{3}{|l|}{ BMI categories, $N(\%)$} \\
\hline $\mathrm{BMI}<20$ & $7(9.6)$ & $4(11.4)$ \\
\hline BMI 20-24 & $40(54.8)$ & $18(51.4)$ \\
\hline BMI 25-29 & $16(21.9)$ & $8(22.9)$ \\
\hline $\mathrm{BMI} \geq 30$ & $10(13.7)$ & $5(14.3)$ \\
\hline \multicolumn{3}{|l|}{ Comorbidities, $N(\%)$} \\
\hline Ear, nose, or throat condition & $3(4.1)$ & $5(14.3)$ \\
\hline Dermatologic condition & $6(8.2)$ & $2(5.7)$ \\
\hline Pulmonary condition & $1(1.4)$ & $3(8.6)$ \\
\hline Hepatic/biliary condition & $2(2.7)$ & $3(8.6)$ \\
\hline Endocrine condition & $8(11.0)$ & $3(8.6)$ \\
\hline Neurologic condition & $8(11.0)$ & $2(5.7)$ \\
\hline Psychiatric condition & $2(2.7)$ & $1(2.9)$ \\
\hline Hematologic condition & $5(6.8)$ & $5(14.3)$ \\
\hline Allergies & $14(19.2)$ & $7(20.0$ \\
\hline Gynecologic condition & $16(21.9)$ & $7(20.0$ \\
\hline \multicolumn{3}{|l|}{ Other health status data, $N(\%)$} \\
\hline Prior surgery & $50(68.5)$ & $24(68.6)$ \\
\hline Major illness within 5 years & $9(12.3)$ & $2(5.7)$ \\
\hline $\begin{array}{l}\text { Prior sexually transmitted } \\
\text { disease }\end{array}$ & $3(4.1)$ & $1(2.9)$ \\
\hline \multicolumn{3}{|l|}{ Maternal history, mean (SD) } \\
\hline No. of pregnancies & $2.8(1.5)$ & $2.5(1.3)$ \\
\hline No. of full-term deliveries & $2.2(0.9)$ & $2.0(0.8)$ \\
\hline Time since last delivery (years) & $7.9(6.4)$ & $8.3(5.5)$ \\
\hline No. of vaginal deliveries & $2.1(1.0)$ & $1.9(0.9)$ \\
\hline
\end{tabular}

${ }^{\mathrm{a}}$ All baseline characteristics were not statistically different $(\alpha=0.05)$ for the Active versus Sham treatment groups.

BMI, body mass index.

tional" at 1, 3, and 6 months postintervention, whereas, the mean FSFI total score for Sham-treated subjects did not reach sexually "functional" at any follow-up time point.

\section{FSFI domain results summary}

The ANCOVA CFB analyses for each FSFI domain of sexual function at 6 months postintervention are presented in Table 2. Baseline values for each FSFI domain were similar for both treatment groups. Subjects in the Active group had greater improvement on all six domains of sexual function than subjects in the Sham group. The AMC from baseline to 6 months shows statistically significant improvements (at the 0.05 significance level) for subjects in the Active treatment group (vs. Sham) in the Arousal, Lubrication, and Orgasm domains of sexual function. There was a borderline significant improvement $(p=0.053)$ in the Desire domain. Among 


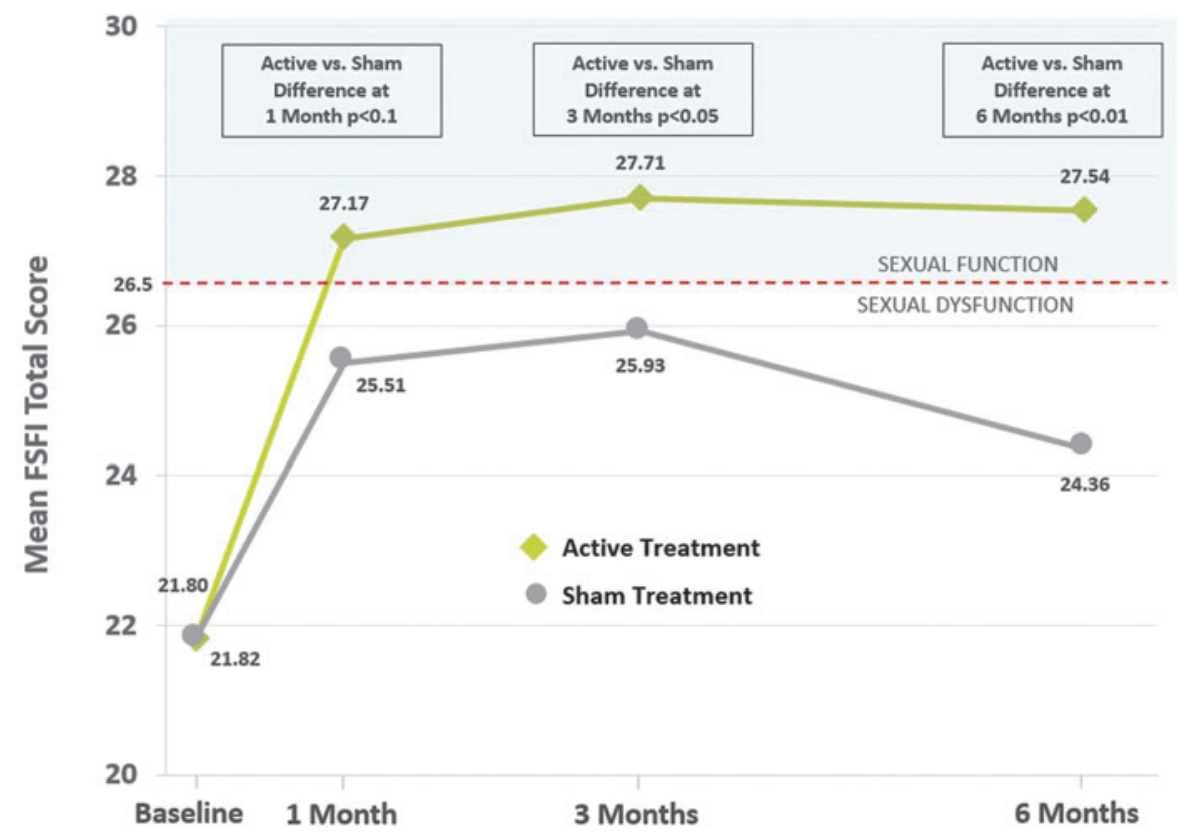

FIG. 3. FSFI total score: mean values at baseline and at each follow-up time point. FSFI, Female Sexual Function Index. Note: The reference line at FSFI total score $=$ 26.5 represents the threshold for classifying female sexual dysfunction (FSD). ${ }^{40}$

Note: The reference line at FSFI total score $=26.5$ represents the threshold for classifying female sexual dysfunction (FSD). ${ }^{40}$

all FSFI domains of sexual function, the greatest differences between Active and Sham treatment were observed for the Arousal and Orgasm domains.

The MCID analyses at 6 months posttreatment are presented in Table 3 . These analyses evaluated the difference in the proportion of Active versus Sham subjects who experienced what they perceived to be a clinically meaningful treatment benefit relative to change on each FSFI domain assessment. For all FSFI domains of sexual function, subjects in the Active treatment group had a greater perception of achieving a clinically meaningful treatment benefit compared to subjects in the Sham group.

The MCID for the FSFI arousal assessment was an improvement of at least 1.0 point from the baseline arousal assessment to the 6-month arousal assessment. Forty-five $(45 / 73 ; 61.6 \%)$ and $14(14 / 35 ; 40.0 \%)$ subjects in the Active and Sham groups, respectively, achieved an improvement of $\geq 1.0$ point on the sexual arousal assessment (baseline vs. 6 month). The MCID odds ratio [OR] (95\% CI) shows subjects in the Active treatment group were more than 2.7 times as likely to achieve a clinically meaningful and statistically significant treatment benefit regarding their perception of sexual arousal compared to Sham-treated subjects $[\mathrm{OR}=2.73$ (1.06-7.04)]. In addition to the FSFI Arousal domain, subjects in the Active treatment group achieved a clinically important and statistically significant improvement regarding their perception of orgasm $[\mathrm{OR}=2.58(1.08-6.18)]$ and desire $[\mathrm{OR}=3.01(1.11-8.17)]$ compared to Sham subjects.

Table 2. Female Sexual Function Index Domains of Sexual Function: Mean Values and Adjusted Mean Change at Baseline and 6 Months Postintervention

\begin{tabular}{|c|c|c|c|c|c|}
\hline FSFI domains & $\begin{array}{l}\text { Treatment } \\
\quad \text { group }\end{array}$ & $\begin{array}{l}\text { Baseline }^{\mathrm{a}} \\
\quad \text { mean }\end{array}$ & $\begin{array}{l}\text { 6-Month } \\
\text { mean }\end{array}$ & $\begin{array}{c}\text { Adjusted }^{\mathrm{b}} \\
\text { mean change }\end{array}$ & $\mathrm{p}-$ value $^{\mathrm{c}}$ \\
\hline Desire & $\begin{array}{l}\text { Active } \\
\text { Sham }\end{array}$ & $\begin{array}{l}2.92 \\
2.90\end{array}$ & $\begin{array}{l}3.72 \\
3.33\end{array}$ & $\begin{array}{l}0.82 \\
0.42\end{array}$ & 0.053 \\
\hline Arousal & $\begin{array}{l}\text { Active } \\
\text { Sham }\end{array}$ & $\begin{array}{l}3.12 \\
3.30\end{array}$ & $\begin{array}{l}4.39 \\
3.80\end{array}$ & $\begin{array}{l}1.27 \\
0.62\end{array}$ & $0.004^{\mathrm{c}}$ \\
\hline Lubrication & $\begin{array}{l}\text { Active } \\
\text { Sham }\end{array}$ & $\begin{array}{l}3.78 \\
3.90\end{array}$ & $\begin{array}{l}5.07 \\
4.59\end{array}$ & $\begin{array}{l}1.30 \\
0.77\end{array}$ & $0.040^{\mathrm{c}}$ \\
\hline Orgasm & $\begin{array}{l}\text { Active } \\
\text { Sham }\end{array}$ & $\begin{array}{l}3.07 \\
3.18\end{array}$ & $\begin{array}{l}4.23 \\
3.53\end{array}$ & $\begin{array}{l}1.24 \\
0.51\end{array}$ & $0.007^{\mathrm{c}}$ \\
\hline Satisfaction & $\begin{array}{l}\text { Active } \\
\text { Sham }\end{array}$ & $\begin{array}{l}3.65 \\
3.35\end{array}$ & $\begin{array}{l}4.60 \\
4.14\end{array}$ & $\begin{array}{l}1.04 \\
0.66\end{array}$ & 0.124 \\
\hline Pain & $\begin{array}{l}\text { Active } \\
\text { Sham }\end{array}$ & $\begin{array}{l}4.85 \\
4.79\end{array}$ & $\begin{array}{l}5.14 \\
4.72\end{array}$ & $\begin{array}{r}0.27 \\
-0.13\end{array}$ & 0.083 \\
\hline
\end{tabular}

\footnotetext{
${ }^{a}$ The baseline FSFI assessment was conducted before the intervention.

${ }^{\mathrm{b}}$ The adjusted mean change was estimated from individual ANCOVA models (for each domain), which included the baseline domain score and treatment group as independent variables.

${ }^{c} p$-value deemed statistically significant as $\leq 0.05$.

ANCOVA, analysis of covariance; FSFI, Female Sexual Function Index.
} 
Table 3. Minimal Clinically Important Difference Analyses at the 6-Month Time Point for Each Female Sexual Function Index Domain of Sexual Function

\begin{tabular}{|c|c|c|c|c|c|c|c|c|}
\hline \multirow{2}{*}{$\frac{\text { FSFI domains }}{\text { Desire }}$} & \multirow{2}{*}{$\begin{array}{c}\text { Treatment } \\
\text { Active } \\
\text { Sham }\end{array}$} & \multirow{2}{*}{$\begin{array}{c}\text { MCID } \\
\text { value }^{\mathrm{a}}\end{array}$} & \multirow{2}{*}{$\begin{array}{l}\mathrm{N} \\
73 \\
35\end{array}$} & \multicolumn{2}{|c|}{$\begin{array}{l}\geq M C I D \\
\mathrm{~N}^{\prime}(\%)\end{array}$} & \multirow{2}{*}{$\begin{array}{c}\text { MCID } \\
{\text { odds } \text { ratio }^{\mathrm{b}}}^{\text {}}\end{array}$} & \multirow{2}{*}{$\begin{array}{c}95 \% C I \\
1.11-8.17\end{array}$} & \multirow{2}{*}{$\frac{\mathrm{p} \text {-value }}{0.031^{\mathrm{c}}}$} \\
\hline & & & & $\begin{array}{l}37.9965 \\
11.998\end{array}$ & $\begin{array}{l}52.1 \\
34.3\end{array}$ & & & \\
\hline Arousal & $\begin{array}{l}\text { Active } \\
\text { Sham }\end{array}$ & 1.0 & $\begin{array}{l}73 \\
35\end{array}$ & $\begin{array}{l}44.9972 \\
14\end{array}$ & $\begin{array}{l}61.6 \\
40.0\end{array}$ & 2.73 & $1.06-7.04$ & $0.037^{\mathrm{c}}$ \\
\hline Lubrication & $\begin{array}{l}\text { Active } \\
\text { Sham }\end{array}$ & 1.0 & $\begin{array}{l}73 \\
35\end{array}$ & $\begin{array}{l}41.9969 \\
15.9985\end{array}$ & $\begin{array}{l}57.5 \\
45.7\end{array}$ & 1.58 & $0.57-4.35$ & 0.376 \\
\hline Orgasm & $\begin{array}{l}\text { Active } \\
\text { Sham }\end{array}$ & 0.5 & $\begin{array}{l}73 \\
35\end{array}$ & $\begin{array}{l}48.9976 \\
16.9995\end{array}$ & $\begin{array}{l}67.1 \\
48.6\end{array}$ & 2.58 & $1.08-6.18$ & $0.034^{\mathrm{c}}$ \\
\hline Satisfaction & $\begin{array}{l}\text { Active } \\
\text { Sham }\end{array}$ & 0.9 & $\begin{array}{l}73 \\
35\end{array}$ & $\begin{array}{l}35.0035 \\
14.413\end{array}$ & $\begin{array}{l}48.0 \\
41.2\end{array}$ & 1.53 & $0.57-4.13$ & 0.400 \\
\hline Pain & $\begin{array}{l}\text { Active } \\
\text { Sham }\end{array}$ & 0.1 & $\begin{array}{l}73 \\
35\end{array}$ & $\begin{array}{l}26.0026 \\
11.0005\end{array}$ & $\begin{array}{l}35.6 \\
31.4\end{array}$ & 2.17 & $0.52-8.98$ & 0.286 \\
\hline
\end{tabular}

$N^{\prime}=$ number of subjects who achieved at least the MCID value.

${ }^{a}$ The MCID value was determined for each FSFI domain of sexual function at the 6-month time point. This value represents the smallest change (6-month value and baseline value) that a subject would identify as clinically important.

${ }^{\mathrm{b}}$ MCID odds ratios were estimated using multivariable logistic regression with treatment group and baseline score as independent variables.

${ }^{c} p$-value deemed statistically significant as $\leq 0.05$.

CI, confidence interval; FSFI, Female Sexual Function Index; MCID, minimal clinically important difference.

\section{Discussion}

Building on two single-arm pilot studies, ${ }^{14,15}$ the VIVEVE I trial was the first, multicenter, randomized, Sham-controlled study to evaluate the efficacy of a nonsurgical modality for the treatment of vaginal introital laxity. For the FSFI domain subanalyses, Active CMRF therapy demonstrated superiority over Sham using this validated assessment of sexual function among subjects with baseline FSD as defined by a baseline FSFI total score $\leq 26.5$. The CMRF procedure was well tolerated and showed an excellent 6-month safety profile (data not presented). No topical anesthetic was required and there were no serious adverse events reported in the Active group. In addition, the percentage of subjects reporting a related adverse event that occurred either during or after treatment was essentially the same in both the Active and Sham groups. In the evaluation of adverse events by the site investigator and medical monitor, adverse events were counted as "Related" if the relationship was recorded as "Possibly Related," "Related," or "Unknown/Undetermined," or if the relationship was missing. Examples of "Related" adverse events common to both groups included individual reports of vaginal discharge, mild uterine cramping, and a sensation of warmth during or following the procedure. There is a more detailed description of adverse events in the primary study publication. ${ }^{38}$

The efficacy results of this subanalysis show statistically significant and clinically important improvements in Arousal, Lubrication, and Orgasm domains associated with Active treatment in the target patient population. While the improvement for the Desire domain showed a clinically important improvement, as assessed by MCID, this did not achieve statistical significance. Improvements were also associated with Active treatment for the Satisfaction and Pain domains; however, these did not achieve statistical significance. The results for the Satisfaction domain are not surprising since this domain incorporates multifactorial elements of overall sexual satisfaction (e.g., emotional closeness with partner). In addition, as women were not preselected for pain with intercourse in this study (indeed, they were excluded with untreated dyspareunia), large changes in this domain would also not be expected.

The positive efficacy results from this trial support the proposed mechanism of action, as well as the safe delivery of minimally invasive CMRF therapy to vaginal tissue in women who have self-reported vaginal laxity and FSD as evaluated by baseline FSFI total scores. The statistically significant and clinically important results seen with CMRF may be explained by an effect on the genitopelvic-clitoral complex by enhancement of the structural integrity by enriched fibroblastic deposited connective tissue. This underlying architectural modification may improve neural, hormonal, and vascular flow to the underlying structural components, including the circumferential crural arms of the clitoral arousal complex, hence enhancing both genital arousal and potentially improving orgasmic intensity, while decreasing orgasmic latency, lending to the patientreported improvements in sexual function observed in the VIVEVE I study in various domains of the FSFI.

While CMRF therapy was associated with statistically significant and clinically important improvements of sexual function (in favor of Active treatment), a short-lived Sham effect at months 1 and 3 was observed. For Sham-treated subjects, improvements diminished by 6 months and the mean FSFI total score for Sham-treated subjects never achieved sexually "functional" status (FSFI total score $>26.5$ ), even at the earlier time points. This is not surprising, as a significant placebo response has been observed in several FSD trials. ${ }^{42-44}$ It also is an established principle in the field of sexual health that an individual's mental perception can have a profound effect on their overall sexual function and satisfaction. ${ }^{45,46}$ If one has a negative impression of one's capacity for sexual function, it can directly impact physiological, biological, and chemical reactivity, and subsequent sexual responsiveness. The Sham effect underscores the importance of conducting rigorous research investigations with adequate follow-up time and a comparator 
group (e.g., Sham or placebo) to ensure the treatment effect is attributable to the intervention and is beyond the effects gained from an office visit or counseling with a healthcare professional alone.

This subanalysis had several limitations worth noting. No control for multiplicity was implemented for the post hoc analyses of the VIVEVE I trial; therefore, results should be interpreted as exploratory or hypothesis generating. In addition, the generalizability of the study findings is restricted to women with self-reported vaginal laxity and FSD as defined by a baseline FSFI total score $\leq 26.5$. Women who were sexually functional (i.e., baseline FSFI total score $>26.5$ ) were not analyzed as part of this subanalysis. That said, a substantial proportion of parous women fall into this category. In the VIVEVE I trial, $66 \%$ of included subjects presented with sexual dysfunction at the screening visit. Finally, early system characteristics made double blinding of treatment assignment difficult to achieve. While all subjects were unaware of their treatment assignment for the entire study duration, the site investigator was aware of treatment assignment. Despite this limitation, similar baseline characteristics and study drop-out rates for subjects in the Active and Sham groups empirically suggest that bias was not introduced by investigator channeling or differential study conduct by treatment assignment throughout the entire duration of trial followup. The robust "Sham" effect in the first 3 months further indicates that study validity was not compromised by single blinding. To mitigate the potential for investigator channeling bias, subjects assigned to the Sham group were permitted to receive the Active CMRF therapy upon study completion.

\section{Conclusion}

This subanalysis of the VIVEVE I trial showed that a single, nonablative CMRF treatment significantly improves overall sexual function (FSFI total score) in women with FSD and selfreported vaginal laxity. Of the six domains of the FSFI, the improvement achieved using CMRF therapy is primarily being driven by the statistically significant and/or clinically important improvements in sexual desire, arousal, lubrication, and orgasm in women with vaginal laxity and baseline sexual dysfunction. The findings of sexual function improvement provide evidence for the clinical utility, and direction for further evaluation, of this novel, single treatment, 30-minute, nonsurgical outpatient modality for a highly prevalent and undertreated condition. Furthermore, these results underscore the importance of conducting rigorous research using a randomized Sham or placebo comparator arm with adequate follow-up time to permit the estimation of a valid treatment effect.

\section{Acknowledgments}

We thank the subjects who participated in the VIVEVE I trial and their families, and the participating investigators and their supporting staff. We would also like to acknowledge Theresa Stern, $\mathrm{PhD}$, for her statistical contributions.

\section{Funding/Support}

The VIVEVE I trial was funded by Viveve Medical, Inc.

\section{Role of the Funder/Sponsor}

Employees and consultants to Viveve Medical, Inc. had a role in the design and conduct of the study; collection, management, analysis, and interpretation of the data; preparation, review, or approval of the article; and decision to submit the article for publication.

\section{Author Disclosure Statement}

M.K., MD: Medical consultant to Viveve Medical, Inc. C.G.R., PhD: Research consultant to Viveve Medical, Inc. B.B.A., PhD, MD, FRCS(C): Consultant and advisory board member for Viveve Medical, Inc. Dr. Allan also received research funding for his involvement both Viveve-sponsored and Investigator-sponsored clinical trials. S.D., MPH: Employee of Viveve Medical, Inc. A.Y., BSc: Former employee of Viveve Medical, Inc. D.W., PhD: Employee of Viveve Medical, Inc.

\section{References}

1. Shifren JL, Monz BU, Russo PA, Segreti A, Johannes CB. Sexual problems and distress in United States women: Prevalence and correlates. Obstet Gynecol 2008;112:970-978.

2. Shifren JL, Johannes CB, Monz BU, Russo PA, Bennett L, Rosen R. Help-seeking behavior of women with selfreported distressing sexual problems. J Womens Health (Larchmt) 2009;18:461-468.

3. Hosseini L, Iran-Pour E, Safarinejad MR. Sexual function of primiparous women after elective cesarean section and normal vaginal delivery. Urol J 2012;9:498-504.

4. Dean N, Wilson D, Herbison P, Glazener C, Aung T, Macarthur C. Sexual function, delivery mode history, pelvic floor muscle exercises and incontinence: A crosssectional study six years post-partum. Aust N Z J Obstet Gynaecol 2008;48:302-311.

5. Millheiser L, Kingsberg S, Chen B, Lukes A, Pauls R, Pope K. Cross-sectional survey of sexual health and vaginal laxity following vaginal delivery. J Sex Med 2010;7:239.

6. Pauls RN, Fellner AN, Davila GW. Vaginal laxity: A poorly understood quality of life problem; a survey of physician members of the International Urogynecological Association (IUGA). Int Urogynecol J 2012;23:1435-1448.

7. McDonald E, Woolhouse H, Brown SJ. Consultation about sexual health issues in the year after childbirth: A cohort study. Birth 2015;42:354-361.

8. Barrett G, Pendry E, Peacock J, Victor C, Thakar R, Manyonda I. Women's sexual health after childbirth. BJOG 2000;107:186-195.

9. Klein MC, Kaczorowski J, Firoz T, Hubinette M, Jorgensen S, Gauthier R. A comparison of urinary and sexual outcomes in women experiencing vaginal and Caesarean births. J Obstet Gynaecol Can 2005;27:332-339.

10. Safarinejad MR, Kolahi AA, Hosseini L. The effect of the mode of delivery on the quality of life, sexual function, and sexual satisfaction in primiparous women and their husbands. J Sex Med 2009;6:1645-1667.

11. Griffiths A, Watermeyer S, Sidhu K, Amso NN, Nix B. Female genital tract morbidity and sexual function following vaginal delivery or lower segment caesarean section. J Obstet Gynaecol 2006;26:645-649.

12. Kingsberg S, Millheiser L. Vaginal laxity after childbirth: Qualitative survey of women's perceptions, effect on changes in self-image and sexual relationships. J Sex Med 2010; 7:127-128.

13. DeRogatis L, Clayton A, Lewis-D'Agostino D, Wunderlich $\mathrm{G}, \mathrm{Fu}$ Y. Validation of the female sexual distress scalerevised for assessing distress in women with hypoactive sexual desire disorder. J Sex Med 2008;5:357-364. 
14. Millheiser LS, Pauls RN, Herbst SJ, Chen BH. Radiofrequency treatment of vaginal laxity after vaginal delivery: Nonsurgical vaginal tightening. J Sex Med 2010;7:3088-3095.

15. Sekiguchi Y, Utsugisawa Y, Azekosi Y, et al. Laxity of the vaginal introitus after childbirth: Nonsurgical outpatient procedure for vaginal tissue restoration and improved sexual satisfaction using low-energy radiofrequency thermal therapy. J Womens Health (Larchmt) 2013;22:775-781.

16. Rosen R, Brown C, Heiman J, et al. The Female Sexual Function Index (FSFI): A multidimensional self-report instrument for the assessment of female sexual function. J Sex Marital Ther 2000;26:191-208.

17. Occhino JA, Trabuco EC, Heisler CA, Klingele CJ, Gebhart JB. Changes in vaginal anatomy and sexual function after vaginal surgery. Int Urogynecol J 2011;22:799-804.

18. Schimpf MO, Harvie HS, Omotosho TB, et al. Society of gynecologic surgeons fellows' pelvic research network. Does vaginal size impact sexual activity and function? Int Urogynecol J 2010;21:447-452.

19. Weber AM, Walters MD, Schover LR, Mitchinson A. Vaginal anatomy and sexual function. Obstet Gynecol 1995; 86:946-949.

20. Krychman ML. Vaginal laxity issues, answers and implications for female sexual function. J Sex Med 2016;13:1445-1447.

21. Elser DM, Mitchell GK, Miklos JR, et al. Nonsurgical transurethral collagen denaturation for stress urinary incontinence in women: 18 -month results from a prospective long-term study. Neurourol Urodyn 2010;29:1424-1428.

22. Elser DM, Mitchell GK, Miklos JR, et al. Nonsurgical transurethral collagen denaturation for stress urinary incontinence in women: 12-month results from a prospective long-term study. J Minim Invasive Gynecol 2009;16:56-62.

23. Dillon B, Dmochowski R. Radiofrequency for the treatment of stress urinary incontinence in women. Curr Urol Rep 2009;10:369-374.

24. Gartry DS, Muir MGK, Marshall J. Excimer laser photorefractive keratectomy. 18-month follow-up. Ophthalmology 1992;99:1209-1219.

25. Seiler T, McDonnell PJ. Excimer-laser photorefractive keratectomy. Surv Ophthalmol 1995;40:89-118.

26. Ivarsen A, Asp S, Hjortdal J. Safety and complications of more than 1500 small-incision lenticule extraction procedures. Ophthalmology 2014;121:822-828.

27. Hodgkinson DJ. Clinical applications of radiofrequency: Nonsurgical skin tightening (Thermage). Clin Plas Surg 2009; 36:261-268.

28. Elsaie ML. Cutaneous remodeling and photorejuvenation using radiofrequency devices. Indian J Dermatol 2009;54: 201-205.

29. Vos JA, Livengood RH, Jessop M, Coad JE. Non-ablative hyperthermic mesenchymal regeneration: A proposed mechanism of action based on the Viveve (TM) model. Paper presented at: Conference on Energy-Based Treatment of Tissue and Assessment VI, Jan 23-24, 2011, San Francisco, CA.

30. Coad J, Vos J. Nonsurgical radiofrequency tightening of the vaginal introitus: A histological study using the sheep vagina Model. J Sex Med 2010;7:131-132.

31. Coad J, Vos J, Curtis A, Krychman M. Safety and mechanisms of action supporting nonablative radiofrequency thermal therapy for vaginal introitus laxity occurring in women after childbirth: Histological study in the sheep vaginal model. J Sex Med 2013;10:175.

32. Hantash BM, Abu Ubeid A, Chang H, Kafi R, Renton B. Bipolar fractional radiofrequency treatment induces neoe- lastogenesis and neocollagenesis. Lasers Surg Med 2009; 41:1-9.

33. Alster TS, Lupton JR. Nonablative cutaneous remodeling using radiofrequency devices. Clin Dermatol 2007;25:487-491.

34. Dover JS, Zelickson B. 14-Physician Multispecialty Consensus Panel. Results of a survey of 5,700 patient monopolar radiofrequency facial skin tightening treatments: Assessment of a low-energy multiple-pass technique leading to a clinical end point algorithm. Dermatol Surg 2007;33:900-907.

35. Weiss RA, Weiss MA, Munavalli G, Beasley KL. Monopolar radiofrequency facial tightening: A retrospective analysis of efficacy and safety in over 600 treatments. J Drugs Dermatol 2006;5:707-712.

36. Zelickson BD, Kist D, Bernstein E, et al. Histological and ultrastructural evaluation of the effects of a radiofrequencybased nonablative dermal remodeling device-A pilot study. Arch Dermatol 2004;140:204-209.

37. Sotomayor M, Bernal GF. Twelve-month results of nonsurgical radiofrequency energy micro-remodeling for stress incontinence. Int Urogynecol J Pelvic Floor Dysfunct 2005; 16:192-196.

38. Krychman M, Rowan CG, Allan BB, et al. Effect of singletreatment, surface-cooled radiofrequency therapy on vaginal laxity and female sexual function: The VIVEVE I randomized controlled trial. J Sex Med 2017;14:215-225.

39. ter Kuile MM, Brauer M, Laan E. The Female Sexual Function Index (FSFI) and the Female Sexual Distress Scale (FSDS): Psychometric properties within a Dutch population. J Sex Marital Ther 2006;32:289-304.

40. Wiegel M, Meston C, Rosen R. The Female Sexual Function Index (FSFI): Cross-validation and development of clinical cutoff scores. J Sex Marital Ther 2005;31:1-20.

41. Meston CM. Validation of the Female Sexual Function Index (FSFI) in women with female orgasmic disorder and in women with hypoactive sexual desire disorder. J Sex Marital Ther 2003;29:39-46.

42. Simon JA, Kingsberg SA, Shumel B, Hanes V, Garcia M, Sand M. Efficacy and safety of flibanserin in postmenopausal women with hypoactive sexual desire disorder: Results of the SNOWDROP trial. Menopause 2014;21:633-640.

43. Katz M, DeRogatis LR, Ackerman R, et al. BEGONIA trial investigators. Efficacy of flibanserin in women with hypoactive sexual desire disorder: Results from the BEGONIA trial. J Sex Med 2013;10:1807-1815.

44. Meston CM, Rellini AH, Telch MJ. Short- and long-term effects of Ginkgo biloba extract on sexual dysfunction in women. Arch Sex Behav 2008;37:530-547.

45. Janik MR, Bielecka I, Pasnik K, Kwiatkowski A, Podgorska L. Female sexual function before and after bariatric surgery: A cross-sectional study and review of literature. Obes Surg 2015;25:1511-1517.

46. Molina-Leyva A, Jimenez-Moleon JJ, Naranjo-Sintes R, Ruiz-Carrascosa JC. Sexual dysfunction in psoriasis: A systematic review. J Eur Acad Dermatol Venereol 2015;29: 649-655.

Address correspondence to: Michael Krychman, MD

Southern California Center for Sexual Health and Survivorship Medicine

1501 Superior Avenue, Suite 201 Newport Beach, CA 92663

E-mail: mkrychman@icloud.com 